\title{
PREVALENCE AND SUSCEPTIBILITY PATTERN OF BACTERIAL UROPATHOGENS AMONG PATIENTS WITH URINARY TRACT INFECTION AT BIRAT MEDICAL COLLEGE TEACHING HOSPITAL OF EASTERN NEPAL
}

\author{
Dewasy $B L^{1^{*}}$, Singh $R K^{1}$, Parajuli $S B^{2}$, Kafle $T^{3}$, Mishra $A^{4}$
}

\begin{abstract}
Affiliation
1. Assistant Professor, Department of Microbiology, Birat Medical College \& Teaching Hospital

2. Assistant Professor, Department of Community Medicine, Birat Medical College \& Teaching Hospital

3. Lecturer, Department of Community Medicine, Birat Medical College \& Teaching Hospital
\end{abstract}

\section{ARTICLE INFO}

Received : 07 March, 2020
Accepted : 26 August, 2020
Published : 05 October, 2020

(C) Authors retain copyright and grant the journal right of first publication with the work simultaneously licensed under Creative Commons Attribution License CC - BY 4.0 that allows others to share the work with an acknowledgment of the work's authorship and initial publication in this journal.

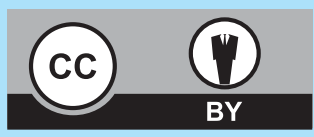

\section{ORA 173}

DOI: https://doi.org/10.3126/bjhs.v5i2.31373

\section{* Corresponding Author}

Dr. Bijoylakshmi Dewasy

Assistant Professor

Department of Microbiology

Kathmandu University- Birat Medical College \& Teaching Hopsital Email ID: bldewasy2012@gmail.com

ORCID ID: https://orcid.org/0000-0000-0002-0115-4701

\section{Citation}

Dewasy BL, Singh RK, Parajuli SB, Kafle T, Mishra A. Prevalence and Susceptibility Pattern of Bacterial Uropathogens Among Patients with Urinary Tract Infection at Birat Medical College Teaching Hospital of Eastern Nepal. BJHS 2020;5(2)12 : 1011-1015.

\begin{abstract}
Introduction

Urinary tract infection (UTI) is a frequent condition encountered in clinical settings. Empirical treatment is common. The treatment without urine culture and sensitivity leads to antimicrobial resistance. This is a major global concern.
\end{abstract}

\section{Objective}

The objective of this study was to find the prevalence and susceptibility pattern of Bacterial Uropathogens among patients with Urinary Tract Infection at Birat Medical College and Teaching Hospital of eastern Nepal.

\section{Methodology}

A cross-sectional study was conducted among patients with UTI attending Birat Medical College and Teaching Hospital from August 2018 to December 2018. The sample size of the study was 530 . Ethical clearance was taken from the Institutional Review Committee of Birat Medical College and Teaching Hospital (Ref: IRC-PA-009/2075-76). Data were entered into Microsoft Excel and analyzed by using SPSS.

\section{Results}

The prevalence of bacterial uropathogens among urine culture was $66.04 \%$. The common uropathogens isolated were E.coli (66.9\%) and Klebsiella spp (15.1\%). E.coli was highly susceptible to Chloramphenicol (100\%) followed by Ceftrixone (82.4\%), Cefpodoxime (77.8\%) and Amikacin (77.9\%); while Klebsiella spp were susceptible to nalidixic acid (40\%) followed by co-trimoxazole (17.9\%).

\section{Conclusion}

Almost 2 out of 3 samples had bacterial uropathogens isolated. E. coli and Klebsiella spp were common. Chloramphenicol and Nalidixic acid were highly susceptible to E.coli and Klebsiella spp respectively.

\section{KEYWORDS}

Prevalence, Nepal, urinary tract infections, teaching hospitals, bacterial Uropathogens 


\section{INTRODUCTION}

Urinary tract infections (UTI) describe microbial colonization and infection of structures of the urinary tract. UTI is categorized by infection site as pyelonephritis, cystitis, and urethritis, and can be classified as uncomplicated or complicated. ${ }^{1}$ UTIs are most prevailing in the community with substantial clinical and financial burdens. ${ }^{2}$ Presence of one lakh or more colony forming units (CFU) per $\mathrm{ml}$ of urine is defined as significant bacteriuria. ${ }^{3}$ This leads criteria has been questioned and bacterial counts of $10^{2}$ or more microorganisms per $\mathrm{ml}$ particularly when accompanied by pyuria (more than $10 \mathrm{WBC} / \mathrm{mm} 3$ ) provide impressive evidence of urinary tract infections in symptomatic young women. ${ }^{4}$ The Infectious Disease Society of America (IDSA) gave a slightly more relaxed consensus definition requiring $10^{5} \mathrm{CFU}$ per $\mathrm{ml}$ to diagnose cystitis and pyelonephritis. ${ }^{3-5}$ There were studies with different prevalence of UTI in the general population of Nepal. Studies done at Sindhupalchowk district reported UTI prevalence as $36.9 \%{ }^{6}$ and at a medical college of Kathmandu was $40.4 \% .{ }^{7}$ A study at Kathmandu Medical College Teaching Hospital found that most common pathogens isolated were E.coli (79.1\%) followed by Klebsiella spp (11.7\%), Citrobacter spp (8.0\%) and Proteus spp (7.0\%). ${ }^{8}$ In another study, the highest percentage of sensitivity was found with Ofloxacin (63.0\%), Ciprofloxacin (62.0\%), Nitrofurantoin (49.1\%) and Amikacin (40.1\%). ${ }^{9}$ Patients attending Birat Medical College and Teaching Hospital has an unknown prevalence of UTI with unknown drug susceptibility pattern. Previous studies conducted in surrounding communities of this medical college teaching hospital reported that selfmedication was $44.04 \%$ with antibiotic being the second most common group for UTI. ${ }^{10}$ Due to this, it creates a gap in the treatment of UTI. The clinicians are following empirical treatment without appropriate culture and sensitivity, which may lead to antibiotic resistance. This study was conducted with an objective to find theprevalence and susceptibility pattern of Bacterial Uropathogens among patients with Urinary Tract Infection at Birat Medical College and Teaching Hospital of eastern Nepal.

\section{METHODOLOGY}

A cross-sectional study was conducted among patients with UTI attending Birat Medical College and Teaching Hospital from August 2018 to December 2018. All the patients suspicious to have urinary tract infection with the history of pain while micturition, frequency, urgency, lower abdominal pain and fever were subjected to urine culture. Bacterial pathogen isolated with antibiotics sensitivity pattern were taken into account and the findings were correlated. The sample size of the study was 530 . Ethical clearance was taken from the Institutional Review Committee of Birat Medical College and Teaching Hospital (Ref: IRC-PA009/2075-76). Data were entered into Microsoft Excel and analyzed by using SPSS. The statistical significance difference is considered at $p<0.05$. Midstream and catheter-catch urine samples (information on how to collect proper sample in sterile container aseptically was given prior to the collection) were collected into a sterile wide-mouth container with all aseptic measures from clinically suspected UTI patients of different age and sex attending either outpatient department (OPD) or inpatient department (IPD) of Birat Medical College and Teaching Hospital. There has not been defined the minimum level of bacteriuria demonstrating an infection of the urinary tract in scientific literature or standardized by microbiological laboratories. As many laboratories define $10^{5}$ colony forming units $(\mathrm{cfu}) / \mathrm{mL}$ urine as the threshold for UTI. ${ }^{11}$ The urine samples from UTI cases were Inoculated aseptically on Blood agar and Cystine Lactose Electrolyte deficient agar (CLED) media by using a calibrated wire loop of $28 \mathrm{G}$ with an internal diameter of 3.26 $\mathrm{mm}$ holding $0.004 \mathrm{ml}$ of urine and incubated overnight at $37^{\circ} \mathrm{C}$ aerobicallyand observed for growth. A specimen was considered positive for UTI if a single organism was cultured at a concentration of $\geq 10^{5} \mathrm{cfu} / \mathrm{mL}^{11}$ Bacterial identification was made using biochemical tests, namely Indole, Citrate, Oxidase, H2S production, lactose fermentation, Urea hydrolysis, gas production, Catalase, Coagulase, and Novobiocin susceptibility test. ${ }^{12}$ Mueller-Hinton agar was used for antimicrobial susceptibility testing (AST) following the Kirby-Bauer disc diffusion method. ${ }^{13}$ Selection of the most appropriate antimicrobial agent requires knowing the organisms identity gram positive/negative. Against a panel of 11 antibiotics; Amoxicillin (10 mcg), Nitrofurantoin (300 $\mathrm{mcg})$, Cephalexin (30 mcg), Cefuroxime (30 mcg), Cefpodoxime (30 mcg), Ceftrixone (30 mcg), Ciprofloxacin (10 mcg), Gentamicin (10 mcg), Nalidixic acid (30 mcg) and Co-trimoxazole $(25 \mathrm{mcg})$. The antimicrobial agents tested were as per Clinical and Laboratory Standards Institutes (CLSI) and The European Committee on Antimicrobial Susceptibility Testing (EUCAST) rules for each isolate. ${ }^{12}$ For the quality control of susceptibility tests Escherichia coli ATCC 25922, E. coli ATCC 35218, Staphylococcus aureus ATCC 29213, Enterococcus faecalis ATCC 29212, E. faecalis ATCC 51299 and Pseudomonas aeruginosa ATCC 27853 strains were used. As per the Clinical Laboratory Standard Institute (CLSI) guidelines susceptibilities were noted as sensitive and resistant based on the diameter of the zone of inhibition. ${ }^{14}$ These antimicrobial agents were selected because of the frequent empirical treatment used by the clinicians. Multidrug resistance was defined as resistance to two or more of the antimicrobials tested. Positive results from urine culture and antimicrobial sensitivity test results were reported to the attending physician for subsequent treatment and follow up.

\section{RESULTS}

In this study, out of 530 cultured urine samples, 350 were found to be positive for uropathogens. So the prevalence of uropathogens was $66.04 \%$. 
Table 1: General characteristics of the study participants having positive culture for uropathogens $(n=350)$

\begin{tabular}{|l|c|c|}
\hline Variables & Frequency $(\mathbf{n})$ & Percentage (\%) \\
\hline Sex & 107 & \\
\hline Male & 243 & 30.6 \\
\hline Female & & 69.4 \\
\hline $\begin{array}{l}\text { Age group } \\
\text { (in Years) }\end{array}$ & 16 & \\
\hline $0-14$ & 85 & 4.6 \\
\hline $15-24$ & 89 & 24.3 \\
\hline $25-39$ & 95 & 25.4 \\
\hline $40-59$ & 45 & 27.1 \\
\hline $60-74$ & 20 & 12.9 \\
\hline$\geq 75$ & & 5.7 \\
\hline
\end{tabular}

As in table 1, the majority of the participants (69.4\%) were female, $27.1 \%$ in the age categories of $40-59$ years. The male to female ratio was $1: 2.3$.
Table 2: Uropathogens isolated from urine samples $(n=350)$

\begin{tabular}{|l|c|c|}
\hline Uropathogens & Frequency (n) & Percentage (\%) \\
\hline Escherichia coli & 234 & 66.9 \\
\hline Klebsiella pneumoniae & 53 & 15.1 \\
\hline Staphylococcus aureus & 29 & 8.3 \\
\hline Enterococcus faecalis & 10 & 2.9 \\
\hline Proteus mirabilis & 9 & 2.6 \\
\hline Staphylococcus saprophyticus & 7 & 2.0 \\
\hline Pseudomonas aeruginosa & 6 & 1.7 \\
\hline Acinetobacter baumannii & 2 & 0.5 \\
\hline
\end{tabular}

The most common uropathogens isolated were Escherichia coli $(66.9 \%)$ followed by Klebsiella pneumoniae (15.1\%) (Table 2).

\begin{tabular}{|c|c|c|c|c|c|c|c|c|c|}
\hline $\begin{array}{l}\text { Age } \\
\text { (Year) }\end{array}$ & E.coli & $\begin{array}{c}\text { Klebsiella } \\
\text { spp }\end{array}$ & $\begin{array}{c}\text { Pseudomonas } \\
\text { spp }\end{array}$ & $\begin{array}{c}\text { Proteus } \\
\text { spp }\end{array}$ & $\begin{array}{c}\text { Enterococc } \\
\text { us spp. }\end{array}$ & $\begin{array}{c}\text { Acinetobacte } \\
r \text { spp }\end{array}$ & S. aureus & \begin{tabular}{|c|} 
S. \\
saprophyticus
\end{tabular} & Total \\
\hline $0-14$ & $7(43.8 \%)$ & $6(37.5 \%)$ & $1(6.2 \%)$ & 0 & 0 & $1(6.2 \%)$ & $1(6.2 \%)$ & 0 & $16(100 \%)$ \\
\hline $15-24$ & $54(63.5 \%)$ & $15(17.6 \%)$ & $1(1.2 \%)$ & $3(3.5 \%)$ & $3(3.5 \%)$ & 0 & $7(8.2 \%)$ & $2(2.4 \%)$ & $85(100 \%)$ \\
\hline $25-39$ & $66(74.2 \%)$ & $11(12.4 \%)$ & $1(1.1 \%)$ & 0 & $3(3.4 \%)$ & 0 & $6(6.7 \%)$ & $2(2.2 \%)$ & $89(100 \%)$ \\
\hline $40-59$ & $72(75.8 \%)$ & $8(8.4 \%)$ & $1(1.1 \%)$ & $3(3.2 \%)$ & $1(1.1 \%)$ & 0 & $10(10.5 \%)$ & 0 & $95(100 \%)$ \\
\hline $60-74$ & $24(53.3 \%)$ & $12(26.7 \%)$ & 0 & $3(6.7 \%)$ & $1(2.2 \%)$ & $1(2.2 \%)$ & $2(4.4 \%)$ & $2(4.4 \%)$ & $45(100 \%)$ \\
\hline$\geq 75$ & $11(55 \%)$ & $1(5 \%)$ & $2(10 \%)$ & 0 & $2(10 \%)$ & 0 & $3(15 \%)$ & $1(5 \%)$ & $20(100 \%)$ \\
\hline Total & $234(66.9 \%)$ & $53(15.1 \%)$ & $6(1.7 \%)$ & $9(2.6 \%)$ & $10(2.9 \%)$ & $2(0.6 \%)$ & $2(8.3 \%)$ & $7(2 \%)$ & $350(100 \%)$ \\
\hline
\end{tabular}

Table 3 shows, the highest prevalence of E.coli was observed in the age group 40-59 years followed by 25-39 years. Similarly, the highest prevalence was observed for Klebsiella pneumoniae at 0-14 years, Pseudomonas aeruginosa at $\geq 75$ years, Proteus sppat 60-74 years, Enterococcus sppat $\geq 75$ years, Acinetobacter spp at 0-14 years, S. aureus at 40-59 years and $S$. saprophyticus at $60-74$ years.

\begin{tabular}{|c|c|c|c|c|c|c|c|c|c|c|}
\hline Drugs & $\begin{array}{c}\text { Antibiotic } \\
\text { susceptibility } \\
\text { pattern }\end{array}$ & E.coli & Klebsiella & Pseudomonas & Proteus & Enterococcus & Acenetobacter & S. aureus & $\begin{array}{c}\text { S. } \\
\text { saprophyticus }\end{array}$ & Total \\
\hline Ampicillin & $\mathrm{R}$ & $5(50 \%)$ & 0 & 0 & 0 & $1(10 \%)$ & 0 & $4(40 \%)$ & 0 & $10(100 \%)$ \\
\hline \multirow{2}{*}{$\begin{array}{l}\text { Nalidixic } \\
\text { Acid }\end{array}$} & $\mathrm{s}$ & $5(50 \%)$ & $4(40 \%)$ & $1(10 \%)$ & 0 & 0 & 0 & 0 & 0 & $10(100 \%)$ \\
\hline & $\mathrm{R}$ & $9(90 \%)$ & 0 & 0 & 0 & 0 & 0 & $1(10 \%)$ & 0 & $10(100 \%)$ \\
\hline \multirow{2}{*}{ Cotrimoxazole } & $\mathrm{s}$ & $36(64.3 \%)$ & $10(17.9 \%)$ & 0 & $1(1.8 \%)$ & $1(1.8 \%)$ & 0 & $8(14.3 \%)$ & 0 & $56(100 \%)$ \\
\hline & $\mathrm{R}$ & $50(80.6 \%)$ & $3(4.8 \%)$ & $0(0.0 \%)$ & $1(1.6 \%)$ & $3(4.8 \%)$ & $2(3.2 \%)$ & $29(4.8 \%)$ & 0 & $62(100 \%)$ \\
\hline \multirow{2}{*}{ Vancomycin } & $\mathrm{s}$ & $2(7.4 \%)$ & 0 & 0 & 0 & $2(7.4 \%)$ & 0 & $21(77.8 \%)$ & \multirow[t]{2}{*}{ NA } & $27(100 \%)$ \\
\hline & $\mathrm{R}$ & 0 & 0 & 0 & 0 & 0 & 0 & 0 & & $1(100 \%)$ \\
\hline Cefpodoxime & $\mathrm{s}$ & $7(77.8 \%)$ & 0 & 0 & 0 & $1(11.1 \%)$ & $1(11.1 \%)$ & 0 & 0 & $9(100 \%)$ \\
\hline Chloramphenicol & $\mathrm{R}$ & $1(33.3 \%)$ & $2(33.3 \%)$ & 0 & 0 & 0 & 0 & & $1(33.3 \%)$ & $4(100 \%)$ \\
\hline \multirow[t]{2}{*}{ Ceftriaxone } & s & $42(82.4 \%)$ & $2(3.9 \%)$ & 0 & $4(7.8 \%)$ & $2(3.9 \%)$ & $1(2 \%)$ & 0 & 0 & $51(100 \%)$ \\
\hline & $\mathrm{R}$ & $42(85.7 \%)$ & $5(10.2 \%)$ & 0 & $1(2 \%)$ & 0 & $1(2 \%)$ & 0 & 0 & $49(100 \%)$ \\
\hline \multirow{2}{*}{ Ciprofloxacin } & $\mathrm{s}$ & $80(67.8 \%)$ & $20(16.9 \%)$ & $2(1.7 \%)$ & $3(2.5 \%)$ & $2(1.7 \%)$ & $1(0.8 \%)$ & $8(6.8 \%)$ & $2(1.7 \%)$ & $118(100 \%)$ \\
\hline & $\mathrm{R}$ & $77(68.5 \%)$ & $10(9 \%)$ & $1(0.9 \%)$ & $3(2.7 \%)$ & $7(6.3 \%)$ & 0 & $10(9 \%)$ & $4(3.6 \%)$ & $112(100 \%)$ \\
\hline \multirow[t]{2}{*}{ Ofloxacin } & $\mathrm{s}$ & $79(64.8 \%)$ & $24(19.7 \%)$ & $4(3.3 \%)$ & $3(2.5 \%)$ & $1(0.8 \%)$ & 0 & $9(7.4 \%)$ & $2(1.6 \%)$ & $122(100 \%)$ \\
\hline & $\mathrm{R}$ & $80(66.1 \%)$ & $13(10.7 \%)$ & $2(1.7 \%)$ & $3(2.5 \%)$ & $5(4.1 \%)$ & $1(0.8 \%)$ & $12(9.9 \%)$ & $5(4.1 \%)$ & $121(100 \%)$ \\
\hline \multirow{2}{*}{ Levofloxacin } & $\mathrm{s}$ & $27(52.9 \%)$ & $13(25.5 \%)$ & $3(5.9 \%)$ & 0 & $1(2 \%)$ & 0 & $6(11.8 \%)$ & $1(2 \%)$ & $51(100 \%)$ \\
\hline & $\mathrm{R}$ & $12(48 \%)$ & $3(12 \%)$ & $1(4 \%)$ & 0 & $3(12 \%)$ & 0 & $4(16 \%)$ & $2(8 \%)$ & $25(100 \%)$ \\
\hline Gentamicin & $\mathrm{s}$ & $15(33.3 \%)$ & $5(11.1 \%)$ & $1(2.2 \%)$ & 0 & NA & 0 & $16(35.6 \%)$ & $2(4.4 \%)$ & $45(100 \%)$ \\
\hline
\end{tabular}


Table 4 shows E. coli were most sensitive (100.0\%) to Chloramphenicol followed by Ceftrixone (82.4\%), Amikacin (77.9\%), Cefpodoxime (77.8\%) and Nitrofurantoin (72.4\%). Moreover, E.coliwas resistant to Nalidixic acid (90\%). Klebsiella sppwas most susceptible to Nalidixic acid (40\%) while resistant to Chloramphenicol (33.3\%).

\section{DISCUSSION}

Urinary tract infection (UTI) is a common problem encountered in the hospital. Antimicrobial resistance to various classes of antibiotics to uropathogens continues to be a major health problem in different parts of the world. ${ }^{15}$ Increasing drug resistance is a great concern to common bacterial infections including UTI. Antimicrobial agents like Amoxicillin, Cotrimoxazole, Nalidixic acid, Cephradine, Ciprofloxacin, and Azithromycin are commonly used to treat many gram-positive and gram-negative infections such as UTI in many developing and underdeveloped countries. Study conducted at surrounding communities of this medical college teaching hospital reported $44.04 \%$ prevalence of self medication and antibiotic was the second most common cause of UTI. ${ }^{10}$ This finding further suggests the growing need of urine culture for prevention of UTI. This study found $66.04 \%$ prevalence of uropathogens. In a study from eastern Nepal, the prevalence was found to be $43.98 \%$ where $91.98 \%$ were unimicrobial. ${ }^{16}$ In a study from India, It was found to be $59.67 \%$ where $94.41 \%$ unimicrobial and $5.59 \%$ polymicrobial. ${ }^{17}$ Other studies also reported similar prevalence. ${ }^{18,19}$ In a study from Duwakot, Bhaktapur, It was found that the prevalence of uropathogens was $13.8 \%{ }^{8}$ In a study from Nepalgunj reported that the prevalence of uropathogens were $27.05 \%{ }^{9}$ It is documented that UTI is more common in females than in males which is also reflected in this study. Similar findings were reported by a recent study done by Deshpande et el. ${ }^{18}$ Escherichia coli (E. coli) is the major aetiological agent of UTI, which accounts for up to $90 \%$ of cases. ${ }^{20}$ In this study, the most common uropathogens was $E$. coli $(66.9 \%)$. Other studies reported similar findings. ${ }^{20,23}$ This study found Klebsiella spp was the second most common uropathogens (15.1\%). In contrast to this study, other studies reported second most common uropathogens was Staphylococcus aureus. ${ }^{22,24}$ A study from Duwakot, Bhaktapur, it was found that the most common pathogenic microorganism isolated was E.coli (79.1\%) followed by Klebsiella spp(11.7\%), Citrobacter spp (3.34\%) and Proteus spp (2.92\%). ${ }^{8}$ In a study from Nepalgunj reported that the most common pathogenic microorganism isolated was E.coli (73.65\%) and Klebsiella spp(19.9\%). ${ }^{9}$

Resistance to antimicrobial agents has been noted since the first use of these agents and is increasing globally. ${ }^{25}$ This study revealed that commonly used antimicrobial agent are resistant to certain uropathogens. E. coli (66.9\%) and $K$. pneumoniae (15.1\%) were resistant to Amoxicillin and Ampicillin is of great importance and implies that these antibiotics cannot be used as empirical therapy for urinary tract infection, particularly in the study area. Similar study from Duwakot, Bhaktapur found that maximum sensitivity with the antibiotics Ofloxacin and Ciprofloxacin. The isolated microorganism demonstrated resistance with Nalidixic Acid and Co-Trimoxazole. ${ }^{8}$ In a study from Nepalgunj reported that the maximum sensitivity was with Nitrofurantoin and Amikacin. ${ }^{9}$

On the other hand very low levels of resistance were detected to antibiotics such as Ceftrixone, Nitrofurantoin and Gentamicin. Similar findings were reported in the studies elsewhere. ${ }^{22,23,26-28}$ Low resistance was observed for these drugs because they are not easily accessible and relatively expensive in price compared to others. It was suggested that, In Nepal transformation of paramedics healthcare practices into policies and public health advocacy at the era of sustainable development goals is the need of time. ${ }^{29}$ As Antibiotic resistance is a growing concern in Nepal and the paramedics are the major prescribers of this. We need to train them for better result. The pharmacovigilance center needs to be established to control growing antibiotic resistance. ${ }^{30}$

\section{CONCLUSION}

Every 2 out of 3 urine samples were positive for uropathogens with more predominance in females and adult age group. $E$. coli and Klebsiella spp were common. Chloramphenicol and Nalidixic acid were highly susceptible to E.coli and Klebsiella spp respectively.

\section{RECOMMENDATIONS}

The isolation of bacterial uropathogens with a higher resistance to commonly used antimicrobials challenges the clinicians for very few options to choose a drug for empirical treatment of UTIs. Therefore, it is important to urge physicians and other health workers in the field on the need of re-evaluation of empirical treatment of UTI. This will reduce unnecessary antibiotic use.

\section{LIMITATION OF THE STUDY}

The study is a hospital-based study and may not truly reflect population level status. Antimicrobial susceptibility testing against pathogenic bacteria in the laboratory is an invitro activity and may not always reflect in vivo activity. There may be some observational errors, especially with the error due to parallax in measuring the inhibition zone diameter.

\section{ACKNOWLEDGEMENT}

The authors would like to acknowledge all supporting laboratory staff and Institutional Review Committee (IRC) of Birat Medical College and Teaching Hospital.

\section{CONFLICT OF INTEREST}

The authors would like to declare no conflict of interest in this study.

\section{FINANCIAL DISCLOSURE}

The authors would like to disclose no any financial support from external agencies. 


\section{REFERENCES}

1. Ejrnæs K. Bacterial characteristics of importance for recurrent urinary tract infections caused by Escherichia coli. Dan Med Bull. 2011;58(4):B4187. https://www.ncbi.nlm.nih.gov/pubmed/ 21466767. PMID: 21466767

2. Cardwell SM, Crandon JL, Nicolau DP, McClure MH, Nailor MD. Epidemiology and economics of adult patients hospitalized with urinary tract infections. Hosp Pract. 2016;44(1):33-40. DOI: 10. 1080/21548331.2016.1133214

3. Kass EH. Asymptomatic infections of the urinary tract. Trans Assoc Am Physicians. 1956;69:56-64. https://www.ncbi.nlm.nih.gov/ pubmed/13380946. PMID: 13380946.

4. Stamm WE, Counts GW, Running KR, Fihn S, Turck M, Holmes KK. Diagnosis of coliform infection in acutely dysuric women. N Engl J Med. 1982;307(8):463-8. http://dx.doi.org/10.1056/NEJM198208193070802.

5. Hooton TM, Stamm WE. Diagnosis and Treatment of Uncomplicated Urinary Tract Infection. Infect Dis Clin North Am. 1997;11(3):551-81. DOI: 10.1016/s0891-5520(05)70373-1.

6. Leela Paudel, Naresh Manandhar, Saroj Sah, Sudesha Khadka, Samikshya Neupane, Sunil Kumar Joshi. Prevalence of urinary tract infection and associated risk factors among women in Sindhupalchowk district, Nepal. International Journal of Community Medicine and Public Health. 2018;5(7). http://dx.doi.org/10.18203/ 2394-6040.ijcmph20182604

7. Khanal LK, Shrestha R, Barakoti A, Timilsina S, Amatya R. Urinary tract infection among males and females-a comparative study. Nepal Med Coll J. 2016;18(3-4):97-9. https://www.nmcth.edu/images/gallery/ Original\%20Articles/Khanal_LK1.pdf.

8. Pradhan B, Pradhan SB. Prevalence of Urinary Tract Infection and Antibiotic Susceptibility Pattern to Urinary Pathogens in Kathmandu Medical College and Teaching Hospital , Duwakot. Birat Journal of Health Sciences. 2017;2(1):134-7. DOI: https://doi.org/10.3126/ bjhs.v2i1.17290.

9. Mahaseth B, Srivastava M, Das CR, Rawat D. Urinary Tract Infection and Antibiotic Susceptibility at Nepalgunj Medical College and Teaching Hospital Kohalpur. Journal of Nepalgunj Medical College.2018. 14, 2018. p. 34-7.http://dx.doi.org/10.3126/ jngmc.v 14i2.21535.

10. Parajuli SB, Mishra A, Heera KC, Bhattarai P, Karki S, Pandit R, et al. Self-Medication Practices in Surrounding Communities of Birat Medical College and Teaching Hospital of Eastern Nepal. JCMSN. 2019;15(1): 45-52. DOI: https://doi.org/10.3126/jcmsn.v15i1. 23021.

11. Schmiemann G, Kniehl E, Gebhardt K, Matejczyk MM, HummersPradier E. The diagnosis of urinary tract infection: a systematic review. Dtsch Arztebl Int. 2010;107(21):361-367. doi:10.3238/ arztebl.2010.0361

12. Akter L, Haque R, Salam MA. Comparative evaluation of chromogenic agar medium and conventional culture system for isolation and presumptive identification of uropathogens. Pak J Med Sci Q. 2014;30(5):1033-8. http://dx.doi.org/10.12669/pjms.305.5243.

13. Bauer AW, Kirby WMM, Sherris JC, Turck M. Antibiotic Susceptibility Testing by a Standardized Single Disk Method. American Journal of Clinical Pathology. 1966.45. p. 493-6. http://dx.doi.org/10.1093/ ajcp/45.4_ts.493.

14. Weinstein MP. Performance Standards for Antimicrobial Susceptibility Testing. 2019. p282. https://books.google.com/ books/about/Performance_Standards_for_Antimicrobial.html?hl= \&id=1VStwgEACAAJ

15. Oliveira FA, Paludo KS, Arend LNVS, Farah SMSS, Pedrosa FO, Souza EM, et al. Virulence characteristics and antimicrobial susceptibility of uropathogenic Escherichia coli strains. Genet Mol Res. 2011;10(4): 4114-25. DOI: 10.4238/2011.October.31.5
16. Chaudhari BK, Singh GK, Parajuli KP, Shrestha K. Incidence and Susceptibility of Uropathogens Isolated among the Patients at Tertiary Care Hospital in Eastern Nepal. JoNMC. 2016;5(2):51-5.DOI: 10.3126/jonmc.v5i2.16318.

17. Rani L, Pinnelli VBK, Hemavathi BS, Rajendran R. Utility Urinary of HiChrome Tract Infection (UTI) agar medium for identification of uropathogens: a comparative study with other conventional media. Journal of chemical and pharmaceutical research. 2012;1(4):95-105. doi: 10.12669/pjms.305.5243.

18. Deshpande KD, Pichare AP, Suryawanshi NM, Davane MS. Antibiogram of gram negative uropathogens in hospitalized patients. International Journal of Recent Trends in Science And Technology. 2011;1(2):56-60.

19. Keah S, Wee E, Chng K, Keah K. Antimicrobial susceptibility of communityacquired uropathogens in general practice. Malays Fam Physician. 2007;2(2):64-9. PMID: 25606083.

20. Ronald $A$. The etiology of urinary tract infection: traditional and emerging pathogens. The American journal of medicine. 2002;113(Suppl 1A):14S-19S. http://dx.doi.org/10.1016/s0002-9343(02) 01055-0.

21. Farajnia S, Alikhani MY, Ghotaslou R, Naghili B, Nakhlband A. Causative agents and antimicrobial susceptibilities of urinary tract infections in the northwest of Iran. Int J Infect Dis. 2009;13(2):140-4. http://dx.doi.org/10.1016/j.ijid.2008.04.014.

22. Tessema B, Kassu A, Mulu A, Yismaw G. Pridominant isolates of urinary tract pathogens and their antimicrobial susceptiblity patterns in Gondar University Teaching Hospital, nothwest Ethiopia. Ethiop Med J. 2007;45(1):61-7.PMID: 17642159.

23. Dromigny JA, Nabeth P, Perrier Gros Claude JD. Distribution and susceptibility of bacterial urinary tract infections in Dakar, Senegal. Int J Antimicrob Agents. 2002;20(5):339-47.http://dx.doi.org/ 10.1016/s0924-8579(02)00196-6.

24. Assefa A, Asrat D, Woldeamanuel Y, G/Hiwot Y, Abdella A, Melesse T. Bacterial profile and drug susceptibility pattern of urinary tract infection in pregnant women at Tikur Anbessa Specialized Hospital Addis Ababa, Ethiopia. Ethiop Med J. 2008;46(3):227-35. PMID: 19271386.

25. Sefton AM. The impact of resistance on the management of urinary tract infections. International Journal of Antimicrobial Agents. 2000; 16(4):489-91.http://dx.doi.org/10.1016/s0924-8579(00)00282-x.

26. Moges AF, Genetu A, Mengistu G. Antibiotic sensitivities of common bacterial pathogens in urinary tract infections at Gondar Hospital, Ethiopia. East African Medical Journal. 2002;79(3). http://dx.doi.org/ 10.4314/eamj.v79i3.8893.

27. Farazi $A$, Jabbariasl $M$. Asymptomatic bacteriuria in pregnancy in the central region of Iran: Frequency, risk factors, and causative organisms. Clinical Epidemiology and Global Health. 2019;7(3):309- 12. http://dx.doi.org/10.1016/j.cegh.2018.09.009.

28. Zvonimir Barišić, AndreaBabić-Erceg, ElmicaBorzić, VinkoZoranić, VanjaKaliterna, MericaCarev. Urinary tract infections in South Croatia: aetiology and antimicrobial resistance. International Journal of Antimicrobial Agents . 2003;22(2):61-4.http:// dx.doi.org/ 10.1016/s0924-8579(03)00233-4.

29. Parajuli SB, Heera KC, Mishra A, Shrestha M. Transformation of Paramedics Healthcare Practices into Policy and Public Health Advocacy in the era of Sustainable Development Goals in the Perspective of Nepal. JCMSN. 2018;14(4):233-4. DOI: https://doi. org/10.3126/jcmsn.v14i4.22246.

30. Shah RC, Karki S, Parajuli SB, Bhattarai P, Chowdhary PK. Pharmacovigilance by World Health Organisation Uppsala Monitoring Center Causality Assessment Algorithm in Medicine Ward of Tertiary Care Hospital of New Delhi. BJHS. 2016;1(1):61-4. DOI: https:// doi.org/10.3126/bjhs.v1i1.17102. 